\title{
Protective effect of carrot juice pretreatment on cadmium- induced oxidative cytotoxic damage to some rat tissues
}

\author{
Embugushiki*, Rebecca Elisha, Mafulul Simon Gabriel And \\ Okoye, Zebulon S.C \\ Department of Biochemistry, College of Medical Sciences, University of Jos, P.M.B. 2084, Jos, Plateau State, \\ Nigeria.
}

\begin{abstract}
The effect of pretreatment with carrot juice on the cytotoxic response of the antioxidant defense systems in the liver and kidneys of rats exposed to mild doses of cadmium was examined. Male wistar strain rats (200-250 g b.wt) were exposed to a single daily oral dose of cadmium (3 $\mathrm{mg} \mathrm{CdCl} / 2 \mathrm{~kg}$ ) in drinking water for two days following a 5-day oral supplementation with carrot juice as drinking water at the end of which membrane lipid peroxidation, ascorbic acid and glutathione contents and activities of antioxidant enzymes catalase, superoxide dismutase, and cadmium content were determined in the liver and kidney samples and the results subjected to statistical analysis. It was found that pretreatment with carrot juice effectively countered $\mathrm{Cd}$ induced membrane lipid peroxidation, depletion of the non-enzymic antioxidants, ascorbic acid, and glutathione, and induction of the antioxidant enzymes catalase and superoxide dismutase in the liver and kidney as well as effectively reduced cadmium accumulation in the liver and kidney and cadmium-induced liver tissue cell injury, all of which effects are consistent with a protective effect of carrot juice The protective effect of carrot juice pretreatment against Cd-induced lipid peroxidation and tissue ascorbic acid and glutathione depletion was more pronounced in the kidney than in the liver. The active antioxidant principle was not determined but is presumed to be carotenoids.
\end{abstract}

Keywords: Cadmium, Carrot, oxidative damage, antioxidant enzymes, non-enzymes endogenous antioxidants.

\section{Introduction}

Cadmium, $\mathrm{Cd}$, a toxic heavy metal, is a ubiquitous industrial and environmental pollutant [1], released into the environment from natural and anthropogenic sources [2] and arising primarily from battery, electroplating, plastics, pigment, fertilizer industries and cigarette smoke. It has been demonstrated that cadmium input into agricultural soils contributes far more to human exposure to cadmium than non-agricultural soils and that cadmium has higher rate of soil - to- plant transference than other non-essential elements [3]. Thus, plant food crops grown on such agricultural soils are significant sources of cadmium in the human diet [4]. Humans become exposed to $\mathrm{Cd}$ through the air (inhalation) and the food chain, with the later being the major route of exposure [5]. Following oral exposure, $\mathrm{Cd}$ is absorbed and delivered to the liver by endogenous intestinal protein metallothionein and from the liver it is rapidly redistributed to other organs with the kidney as the main target organ for Cd toxicity [5].

Studies with experimental animals have shown that exposure to $\mathrm{Cd}$ results in toxic lesions in many species, with Cd showing various mechanisms of toxicity in particular species under different experimental conditions [6]. Severity of Cd intoxication of target organs is dependent on the route, dose, and duration of exposure and it manifests in various forms ranging from acute toxicosis to cancer. Cadmium induces toxic lesions in humans and animals mainly by virtue of its bioaccumulation in target tissues, stimulation of the generation of free radicals and interference with the utilization of essential metals, all of which culminate in oxidative stress [7,8,9,10,11], superoxide anions, nitric oxide and hydrogen peroxide [6], resulting in membrane lipid peroxidation and oxidative deterioration of proteins and DNA and in the process initiating various pathological conditions in humans and animals [6]. For this reason, it has been postulated that ingestion of antioxidant could counter $\mathrm{Cd}$ oxidative damage to target tissue cells. This has been demonstrated in experimental cadmium intoxication: a number of biological antioxidants, notably, the micronutrients vitamin $\mathrm{E}$ and selenium, have reportedly reversed $[12,13]$ or prevented $[14,15,16,17]$ cadmium toxicity to target tissue cells.

Apart from micronutrient supplement, certain biological antioxidant-rich food sources have been shown to also mitigate cadmium intoxication. $[5,10,18]$. In particular, palm oil, a local vegetable oil known to be a rich source of the antioxidant $\beta$-carotene, reportedly reversed the oxidative cytotoxic effects of $\mathrm{Cd}$ on ocular tissue of the rabbit [10]. The palm oil treatment's mitigation of Cd-induced ocular tissue lipid peroxidation and adverse effects on antioxidant enzymes were attributable to the antioxidant intervention of $\beta$-carotene whose 
antioxidant property resides primarily in the ability of its conjugated double bond structure to delocalize the unpaired electrons of free radicals [15].

Carrot, another $\beta$-carotene-rich staple foodstuff, is a major vegetable food crop of the Jos plateau, Nigeria premier carrot growing area. It is extensively consumed in this area which is also home to mining, industrial and agricultural activities that generate $\mathrm{Cd}$ pollution and promote human exposure to $\mathrm{Cd}$ hence, our interest in ascertaining the possible effect of dietary intake of carrot on biological response to chronic exposure to $\mathrm{Cd}$. We report on the protective effect of carrot juice supplemented diet on Cd-induced oxidative cytotoxicity to rat hepatic and renal tissues as determined by tissue $\mathrm{Cd}$ bioaccumulation profiles, oxidative stress biomarkers such as membrane lipid peroxidation, antioxidant defense enzymes activities, non-enzymic tissue antioxidant levels, and biomarkers of tissue cellular damage.

\subsection{Animal treatment}

\section{Materials And Methods}

Wistar strain male rats (b.wt. 230-250 g) obtained from the Animal House Unit, University of Jos, were used in the study. They were maintained on a standard rat diet, 'Vital Feed' (purchased from Grand Cereals and Oil Mills Ltd, Kuru, Nigeria) and tap water as drinking water, ad libitum. The dose of $\mathrm{Cd}\left(\mathrm{CdCl}_{2}\right)$ administered orally to experimental animals in this study was first determined in a pilot study. The $\mathrm{Cd}$ dose used was the lowest in the graded concentration of the $\mathrm{Cd}$ salt tolerated by the rats with quantifiable tissue biochemical changes without fatality. Carrot juice was given as drinking water ad libitum. It was prepared fresh each day from $500 \mathrm{~g}$ carrot using a blender. The crushed paste was squeezed and filtered and the juice obtained was administered as drinking water.

Rats were distributed evenly, 4 rats/cage into four standard plastic-metal rat cages, labeled A-D, respectively. Rats in the four groups were fed the standard 'Vital feed' rat diet and drinking water ad libitum. Rats in group A were fed only with normal rat diet and tap water as drinking water ad libitum and served as the control group. However, each rat in groups $\mathrm{B}$ and $\mathrm{D}$ received fresh carrot juice daily as drinking water. Each rat in group $\mathrm{C}$ received an oral dose of $3.0 \mathrm{mg} \mathrm{CdCl} / 2 \mathrm{~kg} \mathrm{~b}$.wt $/$ day. The carrot juice administration as drinking water was carried out for five days. Thereafter, rats in groups $\mathrm{C}$ and $\mathrm{D}$ were each given one single oral dose $\mathrm{CdCl}_{2}$ in aqueous solution ( $3 \mathrm{mg} \mathrm{CdCl} / 2 \mathrm{~kg}$ b.wt) daily for two days.

\subsection{Tissue sample collection and preparation}

At the end of the feeding experiment, on day 8, each rat under chloroform anaesthesia was sacrificed by decapitation and, in each case, the liver and kidneys were excised and washed in ice-cold normal saline to remove adhering blood particles. Homogenates of liver and kidney samples of each rat were prepared separately by homogenizing $1 \mathrm{~g}$ portion in ice-cold $50 \mathrm{mM}$ Tris-HCl buffer, $\mathrm{pH} 7.4(1: 10, \mathrm{w} / \mathrm{v})$ in an Akia homogenizer. The homogenates were centrifuged at 2,400 xg for $10 \mathrm{~min}$ in a refrigerated low-speed centrifuge and the supernatant (S1) fractions were collected with Pasteur Pipette into plastic vials and stored at $2{ }^{\circ} \mathrm{C}$ pending biochemical analysis. The rest of the kidney and liver samples were used for determination of $\mathrm{Cd}$ content.

\subsection{Biochemical analysis}

Membrane lipid peroxidation, non-enzymic tissue antioxidants (ascorbic acid and glutathione) concentration and antioxidant enzymes (superoxide dismutase, glutathione peroxidase and catalase) activities were determined in the liver and kidney supernatant fractions. Lipid peroxidation was estimated by the thiobarbituric acid reaction method described by Ohkawa et al. [19]. Ascorbic acid content was determined by the method of Roe and Kuether [20] as modified by Tiez [21] and glutathione concentration by the Ellman reaction [22] method as described by Beutler et al. [23]. Catalase activity was assayed by the spectrophotometric method of Aebi et al. [24]; superoxide dismutase activity was assayed as described by Heikkila and Cabbat [25].

\subsection{Tissue cadmium determination}

The cadmium contents of the liver and kidney tissue were estimated with inductively coupled plasma optical emission spectrophotometer (ICP OES) optima 2000DV after wet digestion. 1g portion of the tissue was digested with $20 \mathrm{ml} \mathrm{HNO}-\mathrm{HClO}_{4}$ mixture $(1: 4 \mathrm{v} / \mathrm{v})$ at $100{ }^{\circ} \mathrm{C}$ and the resultant digest diluted to $100 \mathrm{ml}$ with deionized water [18].

\subsection{Statistical analysis}

Statistical analysis of numerical data (expressed as mean $\pm \mathrm{SD}$ ) was done using the statistical package for the social sciences software (SPSS) programme. One way analysis of variance (ANOVA) with post hoc analysis was used to assess the differences between the experimental groups and statistical significance was considered at $\mathrm{p}<0.05$.In addition to ANOVA, the student's t-test was used to compare the various means. 


\section{Results}

3.1 Tissue cadmium concentration

The mean cadmium contents (Table 1) of both the liver and kidney of rats exposed to Cd alone (group C) are in each case, significantly higher $(p<0.05)$ than those of the corresponding tissues in untreated controls (group A). This suggests that the administered $\mathrm{Cd}$ is biologically available and was actively taken up by the kidneys and liver. The mean kidney tissue $C d$ content of rats in group $C$ is significantly higher $(p<0.05)$ than the liver, suggesting that the kidney is more active in bioaccumulation of $\mathrm{Cd}$ than the liver. The liver and kidney of rats exposed to Cd following 5days on carrot juice (group D) had a significantly lower $(\mathrm{p}<0.05) \mathrm{Cd}$ content than the corresponding tissues of rats exposed to $\mathrm{Cd}$ alone (group $\mathrm{C}$ ). This suggests that pretreatment with carrot juice protected against bioaccumulation of $\mathrm{Cd}$. The mean $\mathrm{Cd}$ content of kidney tissue (group D) was significantly higher $(p<0.05)$ than that of the liver, an indication of more active bioaccumulation by the kidney. Pretreatment with carrot juice reduces tissue $\mathrm{Cd}$ levels in the liver and kidney by $41.35 \%$ and $43.35 \%$ respectively. The liver and kidney tissues of the two control groups (A and B), showed traces of cadmium, with the mean values of $\mathrm{Cd}$ content being significantly lower in the carrot juice- treated control (group B) than in rats receiving normal diet alone (group A). This suggests that the rat's feeding environment may have been contaminated by cadmium and that pretreatment with carrot juice reduces tissue bioaccumulation of $\mathrm{Cd}$. In each treatment group, the $\mathrm{Cd}$ content of the kidney is significantly higher than the liver content, suggesting that the kidney is more active in Cd bioaccumulation than the liver even at trace levels.

\subsection{Membrane lipid peroxidation}

The results are summarized in Table 2. In the liver and kidney tissues, the mean concentration of malondialdehyde (MDA) in rats on normal diet given $\mathrm{Cd}$ alone (group $\mathrm{C}$ ) is significantly higher $(\mathrm{p}<0.05)$ than that of the control (group A), suggesting that ingestion of Cd induced lipid peroxidation as determined by MDA. The percentage increase in lipid peroxidation, as determined by MDA, caused by Cd ingestion is $154.46 \%$ and $94.85 \%$ in the liver and kidney respectively. This would suggest that the liver is more susceptible to Cd induced lipid peroxidation than the kidney. The mean MDA levels in the liver and kidney of rats exposed to $\mathrm{Cd}$ following 5days on carrot juice supplementation were significantly lower $(p<0.05)$ than in those given normal diet for 5days prior to $\mathrm{Cd}$ administration. This suggests that pretreatment with carrot juice moderates $\mathrm{Cd}$ induced lipid peroxidation in the tissues examined. Pretreatment with carrot juice reduced the lipid peroxidationinducing effect of $\mathrm{Cd}$ on liver and kidney by 52.545 and $66.67 \%$ respectively, suggesting that the kidney was more susceptible to the protective effect of carrot juice antioxidants than the liver. The mean MDA level is generally higher in the kidney than in the liver except in group B, where the reverse is the case. However, the differences are not statistically significant. The mean MDA levels in the liver and kidney of the control rats (group A) are in each case significantly higher $(p<0.05)$ than those in corresponding tissues of rats pretreated with carrot juice (group B). This would suggest that carrot juice also moderates lipid peroxidation arising from normal intermediary metabolism. (The trace quantities of Cd detected in the controls (Table 1) too insignificant to explain/ account for the MDA level observed in the controls).

\subsection{Non- enzymic tissue antioxidants}

The results of tissue ascorbic acid and glutathione determinations are summarized on Tables 3 and 4, respectively. In each case, the levels of ascorbic acid and glutathione in the liver and kidney of rats exposed to cadmium alone (group $C$ ) is significantly lower $(p<0.05)$ than in the corresponding tissues of untreated control (group A). This would suggests that exposure to cadmium induces depletion of tissue antioxidants ascorbic acid and glutathione in both tissues. The mean ascorbic acid and glutathione contents of the liver and kidney of rats exposed to cadmium alone (group $C$ ) were significantly lower $(p<0.05)$ than in the corresponding tissues of rat pretreated with carrot juice prior to $\mathrm{Cd}$ administration (group D). This suggests that pretreatment with carrot juice protected against cadmium- induced depletion of ascorbic acid and glutathione in the two organs, a further suggestion that carrot juice had a sparing effect on tissue antioxidants ascorbic acid and glutathione. The mean ascorbic acid and glutathione contents of the liver are generally higher than those of the kidney and in each group, the difference is statistically significant $(\mathrm{p}<0.05)$, suggesting that the liver has higher ascorbic acid and glutathione reserves than the kidney. In both the liver and kidney, the mean tissue ascorbic acid and glutathione contents are in each case higher when the normal diet is supplemented with carrot juice (group B) than in rats fed only the normal diet (group A). This suggests that carrot juice had a sparing effect on the tissue antioxidants.

\subsection{Antioxidant enzymes}

The results are summarized on Table 5 . In both the liver and kidneys, the mean activity of each of the antioxidant enzymes was significantly higher $(p<0.05)$ in rats on normal diet exposed to cadmium (group $C$ ) than in the control rats (group A). This would imply that exposure to cadmium induced the activity of each of the two antioxidant enzymes, catalase and superoxide dismutase in the liver and kidney. The degree of induction 
(expressed as \% increase in enzyme activity) in the liver and kidney were $141.82 \%$ and $119.84 \%$ respectively, for catalase, and $53.36 \%$ and $88.88 \%$ for superoxide dismutase. The activity of the antioxidant enzyme catalase in the liver and kidney, and of superoxide dismutase in the liver but not in the kidney were significantly higher $(\mathrm{p}<0.05)$ in rats on normal diet given cadmium (group C) than in those given cadmium following pretreatment with carrot juice (group D). This would suggest that pretreatment with carrot juice moderated the antioxidant enzyme- inducing effect of cadmium on catalase in both tissues and superoxide dismutase in the liver only. Pretreatment with carrot juice reduced the enzyme inducing effect of Cadmium on catalase in the liver and kidney by $45.51 \%$ and $45.79 \%$, respectively, and on the liver superoxide dismutase by $50.74 \%$. Catalase activity in the liver and kidney of rats fed the normal diet supplemented with carrot juice (group B) were significantly lower $(\mathrm{p}<0.05)$ than in the corresponding tissues of rats fed the normal diet alone (group A). A similar trend was observed in the superoxide dismutase activity but the differences were not statistically significant. The results suggest that the ingestion of carrot juice caused a reduction in the level of catalase activity but not SOD, meaning that carrot juice had a sparing effect on catalase.

\subsection{Tissue cell injury enzyme biomarkers}

The results are summarized on Table 6 . The mean activity level in liver of each of the enzymes was significantly higher $(\mathrm{p}<0.05)$ in rats on normal diet exposed to cadmium (group $\mathrm{C}$ ) than in control rats (group A). This would imply that exposure to $\mathrm{Cd}$ caused serious tissue cell damage; hence, more of these cellular enzymes are released. The mean activities of the enzymes were significantly higher $(p<0.05)$ in rats on normal diet given $\mathrm{Cd}$ than in those given $\mathrm{Cd}$ (group C) following pretreatment with carrot juice (group D). This would suggest that pretreatment with carrot juice protect the liver tissue from $\mathrm{Cd}$ induced cell damage thus a lower / normal levels of these enzyme biomarkers. The mean ALT, AST and ALP activities in the liver of rats fed the normal diet supplemented with carrot juice (group B) were significantly lower $(p<0.05)$ than in the corresponding tissue of rat fed the normal diet alone (group A). The results suggest that the ingestion of carrot juice caused a reduction in the level normal metabolic oxidative damage to liver cells.

Table 1: Cadmium content of liver and kidney tissues of rats orally exposed to cadmium following pre- treatment with carrot juice.

\begin{tabular}{|c|c|c|c|}
\hline \multirow[b]{2}{*}{ Group } & \multirow[b]{2}{*}{ Treatment } & \multicolumn{2}{|c|}{ Cadmium concentration $(\mu \mathrm{g} / \mathrm{g}$ tissue $)$} \\
\hline & & Liver & Kidney \\
\hline A & Normal diet + water(Control) & $0.39 \pm 0.014$ & $0.47 \pm 0.021$ \\
\hline B & Normal diet + carrot juice 5 days & $0.22 \pm 0.007^{\mathrm{ab}}$ & $0.30 \pm 0.007^{\mathrm{abc}}$ \\
\hline $\mathrm{C}$ & $\begin{array}{l}\text { Normal diet } 5 \text { days; } \mathrm{Cd} 2 \text { days } \\
\text { Normal diet }+ \text { carrot juice } 5 \text { days; } \mathrm{Cd}\end{array}$ & $4.09 \pm 0.014^{\mathrm{a}}$ & $5.13 \pm 0.49^{\mathrm{ac}}$ \\
\hline $\mathrm{D}$ & 2days & $2.56 \pm 0.106^{\mathrm{ab}}$ & $3.11 \pm 0.0351^{\mathrm{ab}}$ \\
\hline
\end{tabular}

Tabulated values are mean $\pm S D, n=4$, where $n$ is the number of rats in each group.

${ }^{a}$ values are significantly different $(p<0.05)$ from that of the control.

${ }^{b}$ values are significantly different $(p<0.05)$ from that of group treated with $\mathrm{Cd}$ alone.

${ }^{c}$ values are significantly different $(p<0.05)$ from that of the corresponding liver tissue of rats in the same treatment group.

Table 2: Effect of pre-supplementation of normal rat diet with carrot juice on cadmium induced lipid peroxidation in the liver and kidney as determined by malondialdehyde levels

\begin{tabular}{llll}
\hline & & \multicolumn{2}{l}{ Malondialdehyde concentration $(\boldsymbol{\mu g} / \mathbf{g}$ tissue $)$} \\
\cline { 3 - 4 } Group & Treatment & Liver & Kidney \\
\hline A & Normal diet + water(Control) & $23.23 \pm 5.53$ & $31.28 \pm 2.60$ \\
B & Normal diet + carrot juice 5days & $13.34 \pm 0.65^{\mathrm{ab}}$ & $11.04 \pm 0.65^{\mathrm{ab}}$ \\
$\mathrm{C}$ & Normal diet 5days; Cd 2days & $59.11 \pm 4.23^{\mathrm{a}}$ & $60.95 \pm 1.63^{\mathrm{a}}$ \\
& Normal diet + carrot juice 5days;Cd & & $41.17 \pm 0.33^{\mathrm{ab}}$ \\
\hline
\end{tabular}

Tabulated values are mean $\pm S D, n=4$, where $n$ is the number of rats in each group.

${ }^{a}$ values are significantly different $(p<0.05)$ from that of the control.

${ }^{b}$ values are significantly different $(p<0.05)$ from that of group treated with $\mathrm{Cd}$ alone.

${ }^{c}$ values are significantly different $(\mathrm{p}<0.05)$ from that of the corresponding liver tissue of rats in the same treatment group. 
Table 3: Effect of pre-supplementation of normal rat diet with carrot juice on cadmium induced changes in ascorbic acid levels in the liver and kidney of rats

\begin{tabular}{llll}
\hline & & \multicolumn{2}{l}{ Ascorbic acid concentration $(\boldsymbol{\mu g} / \mathbf{g}$ tissue $)$} \\
\cline { 3 - 4 } Group & Treatment & Liver & Kidney \\
\hline A & Normal diet + water(Control) & $1.85 \pm 0.13$ & $0.64 \pm 0.05^{\mathrm{c}}$ \\
B & Normal diet + carrot juice 5days & $2.05 \pm 0.01^{\mathrm{ab}}$ & $0.97 \pm 0.03^{\mathrm{abc}}$ \\
$\mathrm{C}$ & Normal diet 5 days; Cd 2days & $0.77 \pm 0.03^{\mathrm{a}}$ & $0.15 \pm 0.01^{\mathrm{ac}}$ \\
& Normal diet + carrot juice 5days;Cd & & \\
D & 2days & $1.72 \pm 0.01^{\mathrm{b}}$ & $0.44 \pm 0.04^{\mathrm{abc}}$ \\
\hline
\end{tabular}

Tabulated values are mean $\pm S D, n=4$, where $n$ is the number of rats in each group.

a values are significantly different $(\mathrm{p}<0.05)$ from that of the control.

${ }^{b}$ values are significantly different $(\mathrm{p}<0.05)$ from that of group treated with $\mathrm{Cd}$ alone.

${ }^{c}$ values are significantly different $(\mathrm{p}<0.05)$ from that of the corresponding liver tissue of rats in the same treatment group.

Table 4: Effect of pre-treatment with carrot juice on cadmium-induced depletion of rat liver and kidney tissue glutathione

\begin{tabular}{llll}
\hline & & \multicolumn{2}{l}{ Glutathione concentration $(\boldsymbol{\mu g} / \mathbf{g}$ tissue $)$} \\
\cline { 3 - 4 } Group & Treatment & Liver & Kidney \\
\hline A & Normal diet + water(Control) & $1.82 \pm 0.028$ & $1.43 \pm 0.02$ \\
B & Normal diet + carrot juice 5days & $1.92 \pm 0.02^{\mathrm{ab}}$ & $1.48 \pm 0.01^{\mathrm{bc}}$ \\
$\mathrm{C}$ & Normal diet 5days; Cd 2days & $0.71 \pm 0.01^{\mathrm{a}}$ & $0.54 \pm 0.06^{\mathrm{ac}}$ \\
$\mathrm{D}$ & Normal diet + carrot juice 5days;Cd 2days & $1.20 \pm 0.02^{\mathrm{ab}}$ & $1.02 \pm 0.01^{\mathrm{abc}}$ \\
\hline
\end{tabular}

Tabulated values are mean $\pm \mathrm{SD}, \mathrm{n}=4$, where $\mathrm{n}$ is the number of rats in each group.

${ }^{a}$ values are significantly different $(\mathrm{p}<0.05)$ from that of the control.

${ }^{b}$ values are significantly different $(\mathrm{p}<0.05)$ from that of group treated with $\mathrm{Cd}$ alone.

${ }^{c}$ values are significantly different $(\mathrm{p}<0.05)$ from that of the corresponding liver tissue of rats in the same treatment group.

Table 5: The activities of antioxidant enzymes catalase and superoxide dismutase in the liver and kidney of rats exposed to cadmium following feeding carrot juice- supplemented diet

\begin{tabular}{|c|c|c|c|c|c|}
\hline \multirow[b]{2}{*}{ Group } & \multirow[b]{2}{*}{ Treatment } & \multicolumn{2}{|c|}{ Catalase activity (umol/g tissue) } & \multicolumn{2}{|c|}{ SOD activity (umol/g tissue) } \\
\hline & & Liver & Kidneys & Liver & Kidneys \\
\hline A & Normal diet + water(Control) & $5.50 \pm 0.97$ & $6.08 \pm 0.49$ & $34.09 \pm 3.21$ & $40.91 \pm 3.21$ \\
\hline $\mathrm{B}$ & Normal diet + carrot juice 5 days & $2.75 \pm 0.33$ & $2.98 \pm 0.65$ & $32.95 \pm 0.88$ & $36.36 \pm 5.71$ \\
\hline $\mathrm{C}$ & Normal diet 5 days; $\mathrm{Cd} 2$ days & $13.30 \pm 2.27$ & $13.30 \pm 1.62$ & $52.28 \pm 8.94$ & $77.27 \pm 2.15$ \\
\hline $\mathrm{D}$ & $\begin{array}{l}\text { Normal diet }+ \text { carrot juice } 5 \text { days } ; \mathrm{Cd} \\
2 \text { days }\end{array}$ & $9.75 \pm 1.14$ & $9.98 \pm 0.81$ & $43.05 \pm 0.40$ & $70.46 \pm 3.22$ \\
\hline
\end{tabular}

Tabulated values are mean $\pm \mathrm{SD}, \mathrm{n}=4$, where $\mathrm{n}$ is the number of rats in each group.

${ }^{a}$ values are significantly different $(\mathrm{p}<0.05)$ from that of the control.

$\mathrm{b}$ values are significantly different $(\mathrm{p}<0.05)$ from that of group treated with $\mathrm{Cd}$ alone.

${ }^{c}$ values are significantly different $(\mathrm{p}<0.05)$ from that of the corresponding liver tissue of rats in the same treatment group. 
Table 6: Activities of tissue marker enzymes aspartate and alanine aminotransferases, and alkaline phosphatase in the liver of rats exposed to cadmium following supplementation of normal rat diet with carrot juice

\begin{tabular}{lccc}
\hline & \multicolumn{2}{c}{ Liver enzyme activities $(\boldsymbol{\mu} / \mathbf{g}$ tissue $)$} & ALP \\
\cline { 2 - 3 } Group Treatment & AST & ALT & $29.50 \pm 2.12$ \\
\hline A Normal diet + & $7.40 \pm 0.85$ & $3.20 \pm 0.28$ & $23.5 \pm 3.54^{\mathrm{ab}}$ \\
water(Control) & & & \\
B Normal diet + carrot juice & $5.70 \pm 5.45^{\mathrm{ab}}$ & $2.90 \pm 0.14^{\mathrm{b}}$ & $225.00 \pm 21.21^{\mathrm{a}}$ \\
5days & & $71.50 \pm 3.53^{\mathrm{a}}$ & $1587.00 \pm 2.83^{\mathrm{ab}}$ \\
C Normal diet 5days; Cd & $90.45 \pm 3.39^{\mathrm{a}}$ & $51.55 \pm 2.48^{\mathrm{ab}}$ & \\
2days & $69.90 \pm 1.13^{\mathrm{b}}$ & & \\
D Normal diet + carrot juice 5days;Cd 2d &
\end{tabular}

Tabulated values are mean $\pm \mathrm{SD}, \mathrm{n}=4$, where $\mathrm{n}$ is the number of rats in each group.

a values are significantly different $(\mathrm{p}<0.05)$ from that of the control.

${ }^{b}$ values are significantly different $(\mathrm{p}<0.05)$ from that of group treated with $\mathrm{Cd}$ alone.

${ }^{c}$ values are significantly different $(p<0.05)$ from that of the corresponding liver tissue of rats in the same treatment group.

\section{Discussion}

Cadmium accumulates unevenly in human tissues and is concentrated primarily in the liver and kidney [26]. In the current study, cadmium administration to rats leads to a significantly increased accumulation of cadmium in the liver and kidneys of rats treated with cadmium. This is in agreement with the previous studies which showed that oral intake of cadmium induces its accumulation in these tissues as well as alters the enzymatic and non-enzymatic components of antioxidant defence system [17]. Also, the presence in trace quantities, of cadmium in the liver and kidney of rats on the control diets has similarly been observed by other workers $[14,17,18]$. This is a testimony of the ubiquity of cadmium in the food chain and the environment; including the plastic components of the rat cage. Thus, it suggests that the rats feeding environment may have been contaminated by cadmium. However, with pretreatment with carrot juice prior to exposure to cadmium, cadmium concentration in the liver and kidneys, were significantly $(\mathrm{p}<0.05)$ lowered. The decreased cadmium concentration in the liver and kidneys could be explained by its redistribution to other tissues and organs as well as by formation of cadmium-carotenoid complexes or by a carotenoid induced expression of metallothionein which may bind cadmium to form cadmium- metallothionein complexes [26] or by interfering with free radical chain initiation and progression of $\mathrm{Cd}$-induced oxidative damage. The decreased accumulation of cadmium in liver and kidneys after pretreatment with carrots juice prior to exposure to cadmium, indicate that carrot juice diminished the toxic effects of cadmium.

Membrane lipid peroxidation is a major early manifestation of oxidative damage to the liver and kidney tissues by cadmium [15] and it plays an important role in the induction of toxic lesions by many pro-oxidant foreign metal ions like $\mathrm{Cd}[6,17]$. Our findings confirm that exposure to cadmium causes a significant increase in membrane lipid peroxidation in the liver and kidneys of rats. However, pre-treatment with carrot juice was very effective in the prevention of oxidative damage induced by cadmium, which resulted in significantly lower degree of lipid peroxidation in the liver and kidneys. This can be explained by the important role of beta carotene in preventing lipid peroxidation and in protection of integrity and functioning of tissues and cells. This is in accord with reported protective effects of antioxidant nutrients against $\mathrm{Cd}$-induced oxidative stress and lipid peroxidation in the liver and kidney $[12,16,17,27,28]$. It has been suggested that $\mathrm{Cd}$ may induce oxidative stress by producing hydroxyl radicals, superoxide anions, nitric oxide and hydrogen peroxide [6, 11]. The toxicological manifestations of lipid peroxidation include decreased membrane fluidity and function, impaired mitochondrial functions and inhibition of enzymes. MDA is an end product of lipid peroxidation and is frequently measured as an index of this process. The prevention of lipid peroxidation is essential for all aerobic organisms and so the organism is well equipped with antioxidants that directly or indirectly protect cells against the adverse effects of xenobiotics, carcinogens and toxic radicals [29].

The protective role of endogenous non-enzymic antioxidants against oxidative damage by free oxyradicals and the depletion of their tissue reserves in the process have long been documented [15]. They are used up in the course of destroying the oxy-radicals. Our study found that exposure to cadmium induced a significant depletion of ascorbic acid and glutathione in the rat liver and kidney, a lesion which was effectively prevented by pre-supplementation with carrot juice. Depletion of tissue reserves of endogenous antioxidants, ascorbic acid and glutathione, on exposure to $\mathrm{Cd}$ is the expected biologic response since cadmium is known to induce oxidative stress through generation of oxy- radicals [15]. That exposure to cadmium induces depletion of ascorbic acid in the liver and kidney is well documented [11]. The observed sparing effect of carrot juice pre- 
supplementation on Cd-induced depletion of both antioxidants in the rat liver and kidney is consistent with a protective role for antioxidants in Cd toxicity.

There is an increasing body of evidence suggesting that the toxicity of $\mathrm{Cd}$ may be associated with the production of reactive oxygen species (ROS) and that cadmium induces alterations in the activities of antioxidant enzymes such as SOD and catalase [26]. Catalase, superoxide dismutase (SOD), and glutathione peroxidase are the three primary antioxidant enzymes of the endogenous defence systems for the removal of reactive oxygen species as well as protection of cells, tissues and organs from oxidative damage [11]. Upon ingestion, many xenobiotics, including prooxidants, such as 2, 4- dinitrophenyl hydrazine [30], induce the enzymes that metabolize them; that is, when cells are oxidatively challenged antioxidant enzymes levels increases as a protective mechanism. In the current study the results obtained regarding the activities of SOD and catalase in the liver and kidney clearly indicate that exposure to mild doses of cadmium significantly induced enzyme activity which was effectively reversed by pre-treatment with carrot juice. This is in accord with reported protective effects of antioxidant nutrients against $\mathrm{Cd}$-induced oxidative stress and alteration of activities (levels) of antioxidant enzymes in the liver and kidney [15, 17, 28].

The observed marked increases in the activities of aminotransferases and alkaline phosphatase in the liver tissue of $\mathrm{Cd}$-exposed rats are indications that the $\mathrm{Cd}$ bioaccumulation in the liver resulted in cytotoxic injury. They are also a confirmation of the observation on lipid peroxidation in which exposure also caused an increase. It has been demonstrated that $\mathrm{Cd}$ tissue bioaccumulation causes tissue cellular injury by inducing oxidative stress which initiates oxidative tissue cell damage through membrane lipid peroxidation $[6,11]$. Measurement of activities of "marker" enzymes or biomarkers in tissues and body fluids can be used in assessing the degree of assault and the toxicity of a chemical compound on organs/tissues [31, 32]. Such measurements can also be used to indicate tissue cellular damage caused by a chemical compound long before it is revealed by histological techniques [33]. Alkaline phosphatase (ALP), a "marker" enzyme for the plasma membrane and endoplasmic recticulum [34], and aminotranferases (AST and ALT) are frequently used to assess the integrity of the plasma membrane [35] and the functionality of the liver; such that any alteration in the activity of these enzymes would indicate likely damage to the external boundaries of the cell (plasma membrane) [36].

Conversely, a marked decrease in the activities of these marker enzymes would indicate a marked reduction in the degree and rate of tissue cell injury. Thus, the carrot juice-induced reduction in the activities of these marker enzymes observed in the liver of rats given carrot juice prior to $\mathrm{Cd}$ implies a decrease in the rate and magnitude of tissue cell injury and it is also in accord with the observed protective effect of carrot juice against cadmium-induced membrane lipid peroxidation. That is, that carrot juice pre-treatment moderated Cdinduced hepatocytotoxic injury, as determined by the activities of the biomarkers aminotransferases and alkaline phosphatase, probably by counteracting the $\mathrm{Cd}$ induction of tissue membrane damaging oxidative stress and membrane lipid peroxidation.

\section{Conclusion}

In conclusion, our study on the effect of carrot juice pretreatment on all the indicators of cytotoxic response to cadmium exposure determined are consistent with a protective effect against oxidative cytotoxic damage to the susceptible tissues. The evidence suggests an antioxidant protective mechanism. The study did not attempt to specifically identify the active principle but based on the well known antioxidant composition of carrots, carotenoids are presumed as the active antioxidant principle. Meanwhile, it appears from the findings of this study that an organism well nourished with carrot at the time of Cadmium exposure has a more effective defence capability against Cadmium-induced oxidative damage to tissue than otherwise.

\section{References}

[1] H.C. Gonick, Nephrotoxicity of cadmium \& lead, Indian J Med Res 1283, 2008, 35-352.

[2] D. Gaurav, S.Preet and K. K. Dua, Chronic cadmium toxicity in rats: treatment with combined administration of vitamins, amino acids, antioxidants and essential metals, Journal of Food and Drug Analysis, 18(6), 2010,464-470.

[3] International Programme on Chemical Safety (IPCS), Cadmium Environmental Health Criteria 134, Geneva: World Health Organization, 1992.

[4] F.J. Van Assche, "A stepwise model to quantify the relative contribution of different environmental sources to human cadmium exposure," paper to be presented at NiCad '98, Prague, Czech Republic, September 21-22, 1998.

[5] S.O. Asagba, Role of diet in absorption and toxicity of oral cadmium-A review of literature, Afr. J. Biotechnol. 8(25), 2009, 7428436.

[6] M.Waisberg, P.Joseph, B Hale and D.Beyersmann, Molecular and cellular mechanisms of cadmium carcinogenesis: a review, Toxicology 192, 2003, 95-117.

[7] R.Nath, R.Prasad, V.K. Palinal and R.K.Chopra, Molecular basis of cadmium toxicity, Prog Food Nutr Sci., 8(1-2), 1984,109-63.

[8] S. Sarker, P. Yadar, R. Trivedi, A.K. Bansal and D. Bhatnagar, Cadmium-induced lipid peroxidation and the status of the antioxidant system in rat tissues, J. Trace Elem. Med. Biol. 9(3), 1995, 144-149.

[9] M. Valko, H. Morris and M. T. Cronin, Metals, Toxicity and Oxidative Stress. Current Medicinal Chemistry,12, $2005,1161-1208$. 
[10] G.E. Eriyamremu, S.E. Ojimogho, S.O. Asagba, and V.E. Osagie, Palm oil induced changes in ocular tissue lipid peroxidation, antioxidant enzymes and ATPases of rabbits in cadmium toxicity, 2008, 3155-3158.

[11] R.C. Patra, K.R Amiya, and D.Swarup, Oxidative stress in lead and cadmium toxicity and its amelioration, Vet Med Int.,2011,1-2.

[12] S.K. Tandon, S. Singh,S. Prasad, K. Khandekar, V.K. Dwivedi, M. Chatterjee, and N. Mathur, Reversal of cadmium induced oxidative stress by chelating agent, antioxidant or their combination in rat. Toxicol Lett 145, 2003, 211-217.

[13] S.H. Nahed and M.A. Sahar, Reverse effect of vitamin E on oxidative stress, derivatives and conductivity changes of hemoglobin induced by exposure to cadmium, 2007,437-443.

[14] B.I. Ognjanovic, S.D. Markovic, S.Z. Pavlovic, R.V. Zikic, A.S. Stajn, and Z.S. Saicic, Effect of chronic cadmium exposure on antioxidant defense system in some tissues of rats: protective effect of selenium, Physiol. Res. 57, 2008, 403-411.

[15] J.S.F. Swaran, Structural, chemical and biological aspects of antioxidants for strategies against metal and metalloid exposure. Oxidative Medicine and Cellular Longevity 2(4), 2009, 191-206.

[16] K.L. Mehmet, A. Burhan, A. Meryem, T.T. Yeter, A. Cevat and U. Hamdi, Vitamin E protects against oxidative damage caused by cadmium in the blood of rats, 2009,154-160.

[17] S.G. Mafulul and Z.S.C. Okoye, Protective effect of pre-supplementation with selenium on cadmium-induced oxidative damage to some rat tissues. Int. J. Biol. Chem. Sci. 6(3), 2012, 1128-1138.

[18] S.O. Asagba,G.E. Eriyamremu, M.A. Adaikpoh, and A. Ezeoma, Levels of lipid peroxidation, superoxide dismutase and $\mathrm{Na}+/ \mathrm{K}+-$ ATPase in some tissues of rats exposed to a Nigerian diet and cadmium. Biol. Trace Elem. Res. 100 (1), 2004, 075-086

[19] H. Ohkawa, N. Ohishi, and K.Yagi, Assay for lipid peroxides in animal tissues by thiobarbituric acid reaction. Anal Biochem, 95:1979, 351-358.

[20] J.H. Roe and C.A Kuether, Estimation of ascorbic acid. Journal of Biological Chemistry,147, 1943 399-423.

[21] W. Tietz, Fundamentals of Clinical Chemistry, Published by WB Saunders Co. West Washington S.G Philadelphia Pa 19105 USA; 1970, 173-176.

[22] G.L. Ellman, Tissue sulfhydryl groups, Arch. Biochem.. Biophys, 82 (1), 1959, 70-7.

[23] E. Beutler, O. Duron and B.M. Kelly, Improved method for the determination of blood glutathione, J Lab Clin Med. 61, 1963,882888.

[24] U. Aebi, W. Chiu and R. Milligan, Role of catalase on antioxidative defenses, J Struct Biol; 2, 1995, 117-118.

[25] R.E. Heikkila and F. Cabbat, A sensitive assay for superoxide dismutase based on the autoxidation of 6-hydroxydopamine. Analytical Biochemistry 75, 1976, 356-362.

[26] G.H. El-Sokkary, A.A. Nafady, and E.H. Shabash, Melatonin ameliorates cadmium-induced oxidative damage and morphological changes in the kidney of rat. The Open Neuroendocrinology Journal, 2, 2009, 1-9.

[27] S. O. Asagba, G.E. Eriyamremu, E.C. Onyeneke and M. Suru, Influence of a Nigerian-like diet on calcium, phosphate and alkaline phosphatase levels in the plasma and bone of cadmium exposed rats. J. Med. Sci. 6(5), 2006, 758-764.

[28] G. Deepti, P. Shabad, K.K. Dua, 2009. Chronic cadmium toxicity in rats: treatment with combined administration of vitamins, amino acids, antioxidants and essential metals. Journal of Food and Drug Analysis 18(6), 2009, 464-470.

[29] H.C. C. Maduka and Z.S.C.Okoye, The effect of Sacoglottis gabonensis stem bark extract, a Nigeria alcoholic beverage additive, on the natural antioxidant defences during 2,4- dinitrophenylhydrazine-induced membrane peroxidation in vivo.Vascular pharmacology 39,2002,21-31.

[30] S.O. Malomo, Toxicological Implication of Ceftriaxone Administration in Rats. Nig J Biochem \& Mol Biol., 15(1), 2000, 33-38.

[31] M.T. Yakubu, L.S. Bilbis, M. Lawal and M.A. Akanji, Effect of Repeated Administration of sildenafl citrate on selected enzyme activities of liver and kidney of male albino rats. Nig J Pure \& Appl Sci., 18, 2003, 1395-1400.

[32] M.O. Nafiu, M.A. Akanji and M.T. Yakubu, Effect of Aqueous Extract of Cochlospermum Planchonii Rhizome on Some Kidney and Liver Functional Indicies of Albino Rats. Afr J Tradit Complement Altern Med., 8(1), 2011, 22-26.

[33] M.A Akanji, A comparative biochemical study of the interaction of some trypanocides with rat tissue cellular system. Ile-Ife Nigeria: University of Ife; Ph. D. Thesis. 1986.

[34] M. Shahjahan, K.E. Sabitha, J. Malbika, C. S. Shyamala-Devis, Effect of Solanum trilobatum against carbon tetrachloride induced hepatic damage in albino rats. Indian J Med Res, 120, 2004, 194-198.

[35] M.A. Akanji, O.A. Adegoke, O.B. Oloyede, Effect of chronic comsumption of Metabisulphate on the integrity of rat cellular system, Toxicol. 81, 1993, 173-179.

[36] M.T. Yakubu, Aphrodisiac and toxicological evaluation of aqueous extract of Fadogia agrestis (Schweinf Ex Heirn) stem in male rats. Ilorin, Nigeria: University of Ilorin; PhD Thesis, 2006. 